\title{
METODE PENGAMBILAN KEPUTUSAN MULTI KRITERIA TOPSIS UNTUK PENENTUAN PRIORITAS PERBAIKAN PROGRAM PELATIHAN RESPONSIF GENDER
}

\author{
Rohmatulloh \\ Pusat Pengembangan Sumber Daya Manusia Aparatur \\ E-mail: rohmatulloh@esdm.go.id
}

\begin{abstract}
ABSTRAK
Tingkat partisipasi perempuan dalam program pelatihan responsif gender masih rendah. Perbaikan program pelatihan responsif gender dalam rangka meningkatkan kinerja pada penyelenggaraan selanjutnya. Pada umumnya temuan dari hasil evaluasi menggunakan beberapa kriteria menghasilkan beberapa alternatif perbaikan. Tujuan penelitian ini adalah menentukan prioritas perbaikan program. Penelitian ini menggunakan pendekatan kuantitatif dengan menerapkan prosedur TOPSIS. TOPSIS sebagai salah satu metode pengambilan keputusan banyak kriteria mudah digunakan. Berdasarkan hasil penilaian dari perencana yang melakukan dan memahami evaluasi dari unit kerja di lingkungan Badan Diklat ESDM diperoleh prioritas perbaikan, yaitu penyebaran informasi kepada berbagai pihak yang selama ini belum optimal dilakukan. Penggunaan TOPSIS pada penelitian ini dapat digunakan untuk penentuan prioritas perbaikan program lainnya agar menjadi lebih terarah perbaikannya.
\end{abstract}

\section{Kata kunci: Responsif gender, diklat, model logika, TOPSIS}

\section{ABSTRACT}

The level of women's participation in gender-responsive training programs is still low. Improvement of gender-responsive training programs within the framework of improving performance in the subsequent implementation. In general, the findings of the evaluation using several assessments have resulted in several alternative improvements. The purpose of this study is the priority goal of program improvement. This study uses a quantitative request by applying the TOPSIS procedure. TOPSIS as one of the decision-making methods many criteria are easy to use. Based on the results of the assessment of the planners who worked on and evaluated the evaluation of the work unit within the Education and Training Agency, they received priority improvements, namely information dissemination to various parties that had not been optimally carried out. The use of TOPSIS in this study can be used to improve priority programs to become more directed towards continuous improvement.

\section{Keywords: Gender-responsive, training, logic model, TOPSIS}

\section{PENDAHULUAN}

Rendahnya partisipasi atau keikutsertaan perempuan dalam kegiatan diklat responsif gender menjadi salah fokus pada penelitian ini. Pelaksana evaluasi program selanjutnya merumuskan berbagai tindakan perbaikan berdasarkan kriteria atau pedoman yang menjadi acuan. Rumusan alternatif solusi perlu dilakukan pembobotan prioritas, sesuai dengan keterbatasan sumber daya yang dimilikinya. Dalam konteks ini maka perlu dilakukan penentuan prioritas agar upaya perbaikan dapat mencapai hasil yang optimal.

Tujuan penelitian ini adalah menganalisis prioritas perbaikan program pelatihan responsif gender bidang ESDM. Metode yang digunakan untuk penentuan prioritas adalah metode pengam- bilan keputusan kriteria majemuk (multi criteria decision making) TOPSIS (Technique for Order of Preference by Similarity to Ideal Solution). Metode pengambilan keputusan multi kriteria adalah metode yang sering digunakan untuk menyelesaikan masalah pengambilan keputusan dengan banyak kriteria atau atribut. Metode ini banyak ragamnya seperti teori utilitas Multiatribut, Proses Hirarki Analitik (Analytical Hierarchy Process/AHP), teori himpunan fuzzy, Teknik untuk urutan preferensi dengan kemiripan dengan solusi ideal (TOPSIS), dan lainnya (Velasquez \& Hester, 2013).

TOPSIS dikembangkan pertama kali oleh Hwang dan Yoon pada tahun 1981. Prinsip dasar TOPSIS yaitu bahwa alternatif yang terpilih harus 
mempunyai jarak terdekat dari solusi ideal positif (solusi optimal) dan jarak terjauh dari solusi ideal negatif (solusi non optimal). TOPSIS banyak digunakan peneliti dan praktisi dengan alasan karena mudah dan sederhana dalam proses perhitungannya sehingga dapat diselesaikan dengan program komputer spreadsheet (Tavana \& Hatami-marbini, 2011). Kelebihan menerapkan TOPSIS, yaitu proses sederhana, mudah digunakan dengan menggunakan program spreadsheet, jumlah tahapan penyelesaian tetap sama tidak terpengaruh jumlah kriteria atau atribut. Kekurangannya, yaitu penggunaan pengukuran jarak tidak mempertimbangkan korelasi atribut, sulit dalam pembobotan dan menjaga konsistensi penilaian. Sedangkan penerapannya telah banyak dilakukan di berbagai bidang seperti manajemen rantai pasok, sistem manufaktur, bisnis dan pemasaran, lingkungan, sumber daya manusia, dan lainnya (Velasquez \& Hester, 2013). Dalam bidang pendidikan dan pelatihan misalnya untuk mengevaluasi pendekatan yang paling cocok dalam penyelenggaraan e-learning (Mohammed, Kasim, \& Shaharanee, 2018) dan menentukan sekolah terbaik yang dilihat dari kinerja jurusan IPA(Hartono et al., 2018).

\section{Program Pelatihan Responsif Gender}

Program pelatihan responsif gender bidang ESDM merupakan salah satu program yang mengintegrasikan isu Pengarusutamaan Gender (PUG) pada program pengembangan SDM yang sudah ada. Program ini tidak bersifat baru, tetapi hanya memasukkan analisis gender pada beberapa kegiatan pengembangan SDM yang memungkinkan dapat diintegrasikan. Artinya tidak dipaksakan untuk semua kegiatan pengembangan SDM. Program pelatihan responsif gender bidang ESDM pada 2011-2014 memiliki kegiatan sebanyak enam pelatihan. Kegiatan ini dilakukan oleh Pusat dan Balai Diklat, serta perguruan tinggi di lingkungan Badan Diklat ESDM.

Gender merupakan isu penting yang mendapatkan perhatian pemerintah dalam mengelola dan menyebar hasil pembangunan di berbagai sektor. Gender adalah hubungan antara perempuan dan laki-laki yang ditentukan oleh nilai-nilai sosial budaya yang dianut oleh masyarakat mengenai tugas, peran, tanggung jawab, sikap dan sifat bagi perempuan dan laki-laki yang dapat berubah dari waktu ke waktu (Kementerian Pemberdayaan Perempuan dan Perlindungan Anak, 2011). Isu gender menjadi penting karena pembangunan harus melibatkan semua pihak dan hasilnya mesti memberikan manfaat secara adil pada berbagai segmen masyarakat baik segmen laki-laki maupun perempuan sesuai dengan kebutuhan, manfaat, tanggung jawab, dan perannya. Menyadari akan pentingya isu keadilan gender, pemerintah telah mewajibkan kepada seluruh instansi pemerintah pusat dan daerah untuk mengintegrasikan isu gender sebagai arus utama dalam kebijakan, program dan kegiatannya sesuai bidangnya masing-masing (Instruksi Presiden Nomor 9 Tahun 2000 tentang Pengarusutamaan Gender Dalam Pembangunan Nasioal). PUG adalah strategi yang dibangun untuk mengintegrasikan gender menjadi satu dimensi integral dari perencanaan, penyusunan, pelaksanaan, pemantauan, dan evaluasi atas kebijakan dan program pembangunan nasional. Program dan kegiatan yang telah mengakomodir strategi PUG diharapkan dapat mempersempit kesenjangan ketidakadilan gender dalam berpartisipasi mengelola, menikmati hasil, dan manfaat pembangunan di berbagai sektor.

Pengintegrasian program pelatihan responsif gender bidang ESDM dilakukan melalui beberapa tahapan perencanaan dan pelaksanaan program seperti disajikan pada Gambar 1 (Kementerian Pemberdayaan Perempuan dan Perlindungan Anak, 2011). Tahap perencanaan dan pelaksanaan dapat segera terlaksana karena program dan kegiatan tersebut tidak bersifat baru, melainkan dengan memanfaatkan program yang sudah dijalankan dan dimasukkan analisis gender. Tahap evaluasi pelaksanaan program telah dilakukan di akhir periode, namun belum dilakukan secara terstruktur dan mendalam. Tahapan ini perlu ditingkatkan agar dapat dijadikan bahan masukan bagi para pengambil kebijakan untuk menilai apakah pelaksanaan program tersebut memberikan capaian output dan outcome yang positif terhadap upaya menghilangkan pandangan bias gender terhadap perempuan dalam pengelolaan sektor ini dan meningkatkan perannya sesuai dengan kebutuhan, manfaat, dan tanggungjawabnya. 


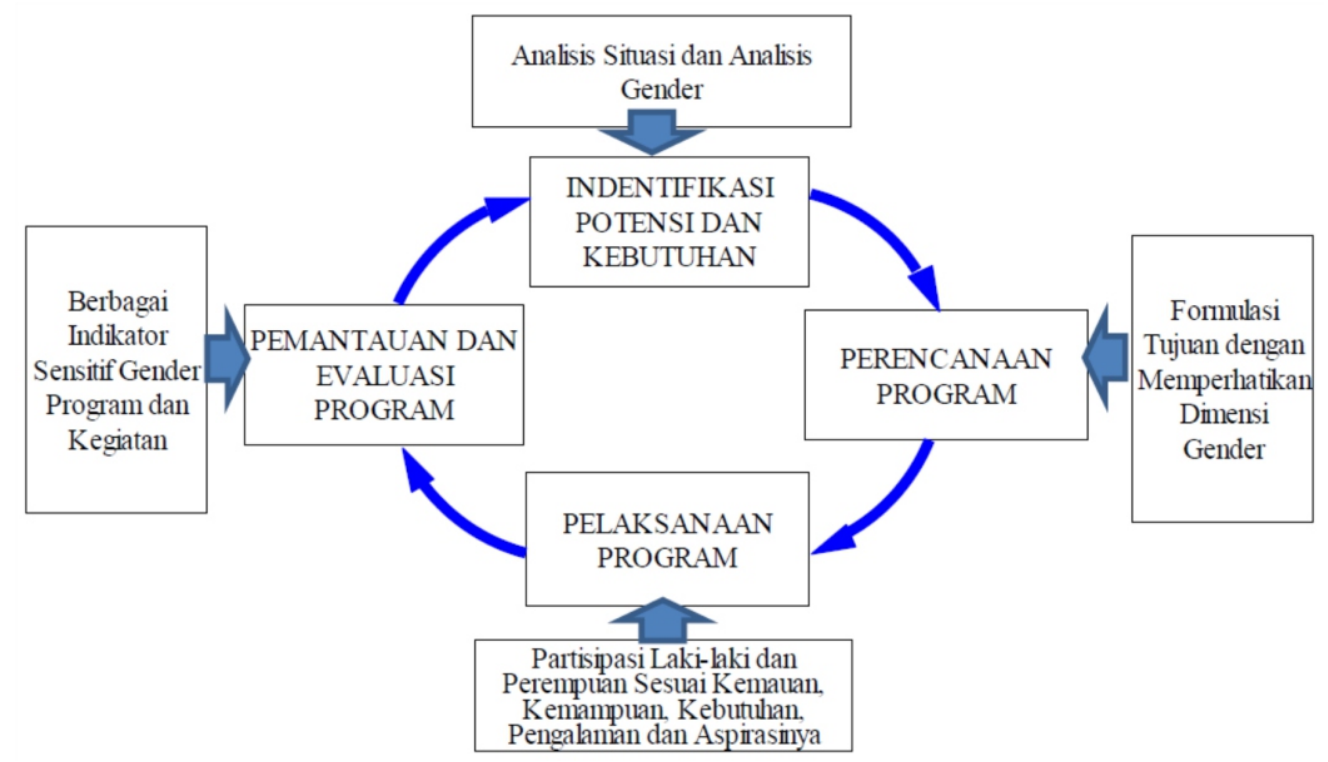

Gambar 1. Perencanaan \& Pelaksanaan Kegiatan yang Responsif Gender

\section{METODE PENELITIAN}

Penelitian ini menggunakan pendekatan kuantitatif. Data primer dikumpulkan menggunakan instrumen kuesioner meliputi aspek kriteria perbaikan dan tindak lanjut perbaikan seperti terlampir. Kuesioner menggunakan aplikasi GoogleForm untuk memudahkan pengisian bagi responden. Responden penelitian adalah perencana yang melakukan dan memahami evaluasi program perwakilan dari masing-masing unit kerja di lingkungan Badan Diklat ESDM. Responden memberikan penilaian perbandingan antar kriteria dan penilaian setiap alternatif perbaikan yang saling terkait dengan kriteria untuk menentukan bobot masing-masing kriteria. Hasil penilaian individu selanjutnya diagregasi untuk diperoleh hasil penilaian kelompok dan dianalisis lebih lanjut menggunakan prosedur metode TOPSIS. Untuk memudahkan perhitungan, digunakan aplikasi spreadsheet. Prosedur analisis seperti terlampir.

\section{HASIL DAN PEMBAHASAN}

Berdasarkan hasil evaluasi kesenjangan program pelatihan responsif gender bidang ESDM diperoleh temuan permasalahan yang seragam, yaitu rendahnya partisipasi atau keikutsertaan perempuan. Rendahnya partisipasi ini disebakan karena rendahnya minat perempuan mengikuti diklat bidang ESDM. Berdasarkan Kamus Besar Bahasa Indonesia (KBBI), pengertian minat adaah kecenderungan hati yang tinggi terhadap sesuatu. Penyebab rendahnya minat, maka perlu ditelusuri tindak lanjut perbaikannya agar minat perempuan mengikuti diklat dapat meningkat sesuai dengan kesadaran dari dalam hatinya. Tindak lanjut perbaikan yang dirumuskan mengacu pada kriteria penentuan prioritas isu strateggis (Astuti et al., 2008), yaitu sebagai berikut:

a. Dapat diselesaikan melalui kompetensi dan sumber daya yang dimiliki (Kriteria 1).

b. Dapat diselesaikan dengan peningkatan kinerja (Kriteria 2).

c. Dapat diselesaikan dengan berkoordinasi kepada pemangku kepentingan yang terkait dengan program PUG (Kriteria 3 ).

d. Dapat membantu meningkatkan kontribusi terhadap program PUG Kementerian ESDM (Kriteria 4)

Mengacu pada empat kriteria di atas, maka rumusan tindakan perbaikan berdasarkan masukan dari penanggungjawab evaluasi program dan kegiatan, yaitu:

a. Mereview mata diklat praktikum (TL1).

b. Sosialisasi kepada seluruh pemangku kepentingan (TL2)

c. Sosialisasi pelatihan responsif gender kepada seluruh pegawai (TL3).

d. Menjalin dan memperkuat kerjasama dengan instansi pemerintah dan masyarakat (TL4).

e. Penyebaran informasi pelatihan responsif gender (TL5).

Untuk meningkatkan efektifitas dalam pelaksanaan tidak lanjut perbaikan, maka dilakukan penentuan prioritas tindakan perbaikan. Tindak lanjut perbaikan yang memiliki bobot kepentingan tinggi akan mendapat perhatian dan aloaksi sumber daya yang lebih dibandingkan tindakan 
perbaikan yang memiliki tingkat kepentingan yang rendah. Berdasarkan identifikasi kriteria dan tindak lanjut perbaikan maka struktur model hirarki evaluasi prioritas berdasarkan hasil pengolahan data disajikan seperti pada Gambar 2 .

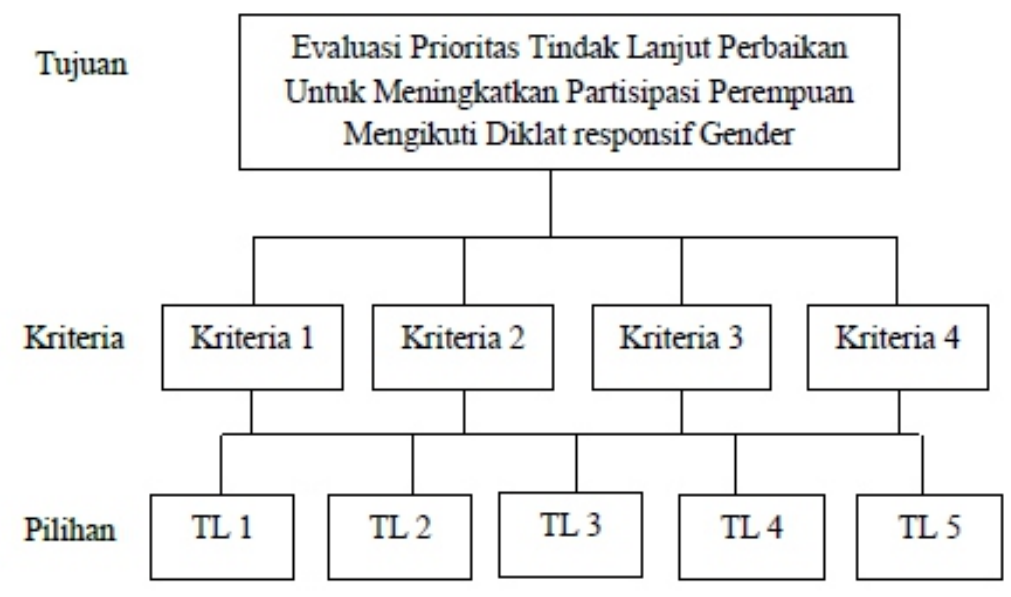

Gambar 2 Stuktur Model Hirarki Evaluasi Prioritas Perbaikan

Penerapan TOPSIS untuk evaluasi prioritas tindak lanjut perbaikan. Matriks hasil penilaian kelompok setiap tindak lanjut perbaikan terkait dengan kriteria disajikan pada Tabel 1. Nilai bobot kriteria diasumsikan sesuai denagn tingkat kepentingannya masing-masing. Hasil akhir perhitungan jarak antara nilai setiap alternatif terhadap solusi ideal positif dan negatif, dan urutan prioritas pilihan (relative closeness) disajikan pada Tabel 2.

Tabel 1 Matriks Keputusan Kelompok

\begin{tabular}{|c|c|c|c|c|}
\hline Bobot & 0,50 & 0,30 & 0,10 & 0,10 \\
\hline & $\mathrm{C} 1$ & $\mathrm{C} 2$ & $\mathrm{C} 3$ & $\mathrm{C} 4$ \\
\hline & \multicolumn{3}{|c|}{ (1=sulit diselesaikan; ...; 5=mudah diselesaikan) } & $\begin{array}{c}(1=\text { sedikit berkontribusi; } \\
\ldots ; 5=\text { berkontribusi besar })\end{array}$ \\
\hline TL 1 & 3,9 & 4,7 & 4,3 & 4,2 \\
\hline TL 2 & 3,6 & 4,2 & 4,4 & 4,4 \\
\hline TL 3 & 4,2 & 4,3 & 4,0 & 3,3 \\
\hline TL 4 & 3,4 & 4,4 & 4,7 & 4,4 \\
\hline TL 5 & 4,1 & 4,4 & 4,6 & 4,2 \\
\hline
\end{tabular}

Tabel 2 Prioritas Perbaikan

\begin{tabular}{|c|c|c|c|c|}
\hline Alternatif perbaikan & $D_{i}^{+}$ & $D_{i}^{-}$ & $R C_{i}$ & Prioritas \\
\hline TL 1 & 0,0198 & 0,0308 & 0,6091 & 3 \\
\hline TL 2 & 0,0410 & 0,0143 & 0,2588 & 4 \\
\hline TL 3 & 0,0171 & 0,0452 & 0,7261 & 2 \\
\hline TL 4 & 0,0456 & 0,0153 & 0,2513 & 5 \\
\hline TL 5 & 0,0097 & 0,0408 & 0,8080 & 1 \\
\hline
\end{tabular}

Berdasarkan hasil evaluasi matrik keputusan kelompok dengan TOPSIS diketahui bahwa prioritas tindak lanjut perbaikan yang perlu mendapatkan perhatian adalah (1) melakukan upaya penyebaran buku informasi pelatihan kepada semua pihak. Prioritas kedua sampai keempat secara berturut-turut yaitu: (2) sosialisasi pelatihan responsif gender kepada kepada seluruh pegawai Badan Diklat ESDM agar program ini tidak hanya diketahui oleh para penyusun program 
dan penyelenggaran diklat, (3) mereview mata diklat praktikum, (4) sosialisasi tentang pentingnya mengetahui manfaat dan pengelolaan sektor ESDM kepada seluruh pemangku kepentingan khususnya segmen perempuan dengan mengikuti kegiatan diklat responsif gender bidang ESDM, dan (5) Menjalin kerjasama dalam proses rekrutmen peserta perempuan instansi pemerintah dan masyarakat. Prioritas tindak lanjut perbaikan ini dapat dilakukan dengan kompetensi dan sumber daya yang dimiliki organisasi saat ini serta dengan meningkatkan kinerjanya masing-masing prioritas.

\section{PENUTUP}

Hasil evaluasi diperoleh temuan bahwa tingkat partisipasi atau keikutsertaan perempuan yang mengikuti program pelatihan masih belum optimal. Oleh karena itu prioritas tindak lanjut perbaikan secara menyeluruh seperti review mata diklat, penyebaran informasi, sosialisasi program ke internal dan eksternal, serta penjalinan kerjasama dengan berbagai pihak harus dilakukam. Dengan upaya ini diharapkan pelaksanaan program pelatihan dapat lebih baik kinerjanya dari waktu ke waktu.

\section{DAFTAR PUSTAKA}

Astuti, W., Rahayu, M. J., Rutiana, Mulyanto, Hakim, L., \& Sulistio, H. (2008). Tata Cara Penyelenggaraan Klinik Konsultasi Penyusunan Renstra-Renja SKPD. Surakarta: Pusat Informasi dan Pembangunan Wilayah LPPM Universitas Sebelas Maret.

Hartono, Helmiati, Yendra, R., Anwar, K., Nizam Muhaijir, M., Rahma, A. N., \& Fudholi, A. (2018). Analysis of the best high school ranking determination with technique methods or others preference by similarity to ideal solution (TOPSIS). International Journal of Mechanical Engineering and Technology, 9(13), 650657.

Kementerian Pemberdayaan Perempuan dan Perlindungan Anak. (2011). Panduan Monitoring Evaluasi Pelaksanaan Perencanaan dan Penganggaran yang Responsif Gender (PPRG). Jakarta: Kementerian Pemberdayaan Perempuan dan Perlindungan Anak.

Mohammed, H. J., Kasim, M. M., \& Shaharanee, I. N. (2018). Evaluation of E-learning approaches using AHP-TOPSIS technique. Journal of Telecommunication, Electronic and Computer Engineering, 10(110), 710.

Tavana, M., \& Hatami-marbini, A. (2011). Expert Systems with Applications A group AHPTOPSIS framework for human spaceflight mission planning at NASA. Expert Systems With Applications, 38(11), 1358813603. https://doi.org/10.1016/j.eswa.2011.04.108

Tsaur, R. C. (2011). Decision risk analysis for an interval TOPSIS method. Applied Mathematics and Computation, 218(8), $\begin{array}{llllllll}4 & 2 & 9 & 5 & 4 & 3 & 0 & 4\end{array}$. https://doi.org/10.1016/j.amc.2011.10.001

Velasquez, M., \& Hester, P. (2013). An analysis of multi-criteria decision making methods. International Journal of Operations Research, 10(No. 2), 5666.

Zhang, Z. (2014). An approach to multi-attribute group decision making and its application to project risk assessment. Journal of Software, 9 ( 2 ), 4044408 . https://doi.org/10.4304/jsw.9.2.404-408 


\section{LAMPIRAN KUESIONER}

Pertanyaan 1: Untuk meningkatkan minat perempuan mengikuti diklat responsif gender bidang ESDM. Bagaimana pendapat saudara tentang tindak lanjut perbaikan di bawah ini yang dapat diselesaikan melalui kompetensi dan sumber daya yang dimiliki Badan Diklat ESDM saat ini?

1.1. Review mata diklat praktikum agar felksibel untuk peserta perempuan

1.2. Sosialisasi diklat responsif gender kepada seluruh pemangku kepentingan

1.3. Sosialisasi diklat responsif gender kepada seluruh pegawai Badan Diklat ESDM

1.4. Menjalin dan memperkuat kerjasama dengan instansi pemerintah dan masyarakat untuk rekrutmen peserta diklat perempuan

1.5. Penyebaran informasi diklat responsif gender bidang ESDM

Pertanyaan 2: Untuk meningkatkan minat perempuan mengikuti diklat responsif gender bidang ESDM. Bagaimana pendapat saudara tentang tindak lanjut perbaikan di bawah ini yang dapat diselesaikan dengan peningkatan kinerja pegawai dan sumber daya lainnya Badan Diklat ESDM?

2.1. Review mata diklat praktikum agar felksibel untuk peserta perempuan

2.2. Sosialisasi diklat responsif gender kepada seluruh pemangku kepentingan

2.3. Sosialisasi diklat responsif gender kepada seluruh pegawai Badan Diklat ESDM

2.4. Menjalin dan memperkuat kerjasama dengan instansi pemerintah dan masyarakat untuk rekrutmen peserta diklat perempuan

2.5. Penyebaran informasi diklat responsif gender bidang ESDM

Pertanyaan 3: Untuk meningkatkan minat perempuan mengikuti diklat responsif gender bidang ESDM. Bagaimana pendapat saudara tentang tindak lanjut perbaikan di bawah ini yang dapat diselesaikan dengan berkoordinasi kepada pemangku kepentingan yang terkait dengan program pengarusutamaan gender (PUG)?

3.1. Review mata diklat praktikum agar felksibel untuk peserta perempuan

3.2. Sosialisasi diklat responsif gender kepada seluruh pemangku kepentingan

3.3. Sosialisasi diklat responsif gender kepada seluruh pegawai Badan Diklat ESDM

3.4. Menjalin dan memperkuat kerjasama dengan instansi pemerintah dan masyarakat untuk rekrutmen peserta diklat perempuan

3.5. Penyebaran informasi diklat responsif gender bidang ESDM
$1=$ Sangat tidak mudah diselesaikan

$2=$ Tidak mudah diselesaikan

$3=$ Moderat

$4=$ Mudah diselesaikan

$5=$ Sangat mudah diselesaikan
$1=$ Sangat tidak mudah diselesaikan

$2=$ Tidak mudah diselesaikan

$3=$ Moderat

$4=$ Mudah diselesaikan

$5=$ Sangat mudah diselesaikan
$1=$ Sangat tidak mudah diselesaikan

$2=$ Tidak mudah diselesaikan

$3=$ Moderat

$4=$ Mudah diselesaikan

$5=$ Sangat mudah diselesaikan 
Pertanyaan 4: Dalam hal penentuan prioritas perbaikan untuk meningkatkan minat perempuan mengikuti diklat responsif gender bidang ESDM. Bagaimana pendapat saudara tentang pilihan tindak lanjut perbaikan yang dapat membantu meningkatkan kontribusi Badan Diklat ESDM pada program PUG Kementerian ESDM.

\begin{tabular}{|c|c|}
\hline Review mata diklat praktikum agar felksibel untuk peserta perempuan & \multirow{5}{*}{$\begin{aligned} 1= & \text { Sangat tidak } \\
& \text { berkontribusi } \\
2= & \text { Tidak } \\
& \text { berkontribusi } \\
3= & \text { Moderat } \\
4= & \text { Mudah } \\
& \text { berkontribusi } \\
5= & \text { Sangat } \\
& \text { berkontrbusi }\end{aligned}$} \\
\hline $\begin{array}{l}\text { Sosialisasi diklat responsif gender kepada seluruh pemangku } \\
\text { kepentingan }\end{array}$ & \\
\hline $\begin{array}{l}\text { Sosialisasi diklat responsif gender kepada seluruh pegawai Badan Diklat } \\
\text { ESDM }\end{array}$ & \\
\hline $\begin{array}{l}\text { Menjalin dan memperkuat kerjasama dengan instansi pemerintah dan } \\
\text { masyarakat untuk rekrutmen peserta diklat perempuan }\end{array}$ & \\
\hline Penyebaran informasi diklat responsif gender bidang ESDM & \\
\hline
\end{tabular}

Lampiran prosedur analisis terdiri dari beberapa tahapan, yaitu sebagai berikut:

1. Membuat matrik keputusan individu (Tsaur, 2011)

Sebagai contoh matrik keputusan terdiri dari of $n$ alternatif perbaikan, $A_{1}, A_{2}, \ldots, A_{n}$ and $m$ kriteria atau atribut, $C_{1}, C_{2}, \ldots, C_{m}$. Perencana melakukan evaluasi setiap alternatif perbaikan yang terkait dengan setiap kriteria dan hasilnya dibentuk matrik $\mathrm{X}=\left(\mathrm{x}_{\mathrm{ij}}\right)_{\mathrm{nxm}} \mathbf{X}=\left(x_{i j}\right)_{n \times m}$ sebagai berikut $:\left(\mathrm{x}_{\mathrm{ij}}\right)_{\mathrm{nxm}}$

$$
\mathbf{X}=\left[\begin{array}{cccccc}
x_{11} & x_{12} & \cdots & x_{1 j} & \cdots & x_{1 m} \\
x_{21} & x_{22} & \cdots & x_{2 j} & \cdots & x_{2 m} \\
\vdots & \vdots & \cdots & \vdots & \cdots & \vdots \\
x_{i 1} & x_{i 2} & \cdots & x_{i j} & \cdots & x_{i m} \\
\vdots & \vdots & \cdots & \vdots & \cdots & \vdots \\
x_{n 1} & x_{n 2} & \cdots & x_{n j} & \cdots & x_{n m}
\end{array}\right]
$$

2. Membuat matriks keputusan agregat (Zhang, 2014)

Misalkan ada beberapa $p$ perencana yang melakukan penilaian, $X_{k}=\left(x_{i j}^{(k)}\right)_{n x m}, k=$ $1,2, \ldots, p$, matrik keputusan diberikan oleh perencana $k$-th. Untuk mengagreasi semua matrik keputusan individu $X_{k}$ ke dalam sebuah kumpulan matrik keputusan $X=\left(x_{i j}\right)_{n x m}$, digunakan persamaan:

$$
x_{i j}=\sum_{k=1}^{p} \lambda_{k} a_{i j}^{(k)}
$$

$\lambda_{k}$ adalah bobot penilaian untuk setiap perencana yang memberikan penilaian atau evaluasi $k$-th, di mana $\sum_{k=1}^{p} \lambda_{k}=1$. Jika perencana memiliki bobot yang sama karena memiliki pemahaman yang sama terhadap masalah ini maka $\lambda_{k}=1 / p$. Jadi persamaan matrik keputusan agregat:

$$
x_{i j}=1 / p \sum_{k=1}^{p} a_{i j}^{(k)}
$$


3. Penentuan prioritas menggunakan TOPSIS (Tsaur, 2011)

Menghitung matrik keputusan yang dinormalisasi dan dibobotkan menggunakan persamaan sebagai berikut:

$$
\begin{gathered}
n_{i j}=\frac{x_{i j}}{\sqrt{\sum_{k=1}^{n} x_{k j}^{2}}}, \quad i=1,2, \ldots, n ; j=1,2, \ldots, m . \\
v_{i j}=w_{j} n_{i j}, \quad i=1,2, \ldots, n ; j=1,2, \ldots, m .
\end{gathered}
$$

Selanjutnya menghitung Positive Ideal Solution (PIS) dan Negative Ideal Solution (NIS) enagn persamaan sebagai berikut. $\Omega_{b}$ dan $\Omega_{c}$ adalah kriteria manfaat (benefit) dan kriteria biaya (cost).

$$
\begin{aligned}
& P I S=A^{+}=\left\{v_{1}^{+}, v_{2}^{+}, \ldots, v_{m}^{+}\right\}=\left\{\left(\max _{i} v_{i j} \mid j \in \Omega_{b}\right),\left(\min _{i} v_{i j} \mid j \in \Omega_{c}\right)\right\}, \\
& N I S=A^{-}=\left\{v_{1}^{-}, v_{2}^{-}, \ldots, v_{m}^{-}\right\}=\left\{\left(\min _{i} v_{i j} \mid j \in \Omega_{b}\right),\left(\max _{i} v_{i j} \mid j \in \Omega_{c}\right)\right\},
\end{aligned}
$$

Menghitung pengukuran separasi setiap alternatif dari PIS dan NIS, serta menghitung Relative Closeness (RC) setiap alternatif untuk mendapatkan solusi ideal. Nilai RC yang paling tinggi mengindikasikan alternatif terbaik.

$$
\begin{array}{cr}
D_{i}^{+}=\sqrt{\sum_{j=1}^{m}\left(v_{i j}-v_{i j}^{+}\right)^{2}}, & i=1,2, \ldots, n . \\
D_{i}^{-}=\sqrt{\sum_{j=1}^{m}\left(v_{i j}-v_{i j}^{-}\right)^{2}}, & i=1,2, \ldots, n . \\
R C_{i}=\frac{D_{i}^{-}}{D_{i}^{+}+D_{i}^{-}}, & i=1,2, \ldots, n .
\end{array}
$$

